\title{
Changes in Inflammatory Biomarkers Across Weight Classes in a Representative US Population: A Link Between Obesity and Inflammation
}

\author{
Xuan-Mai T. Nguyen • John Lane • Brian R. Smith • \\ Ninh T. Nguyen
}

Received: 31 December 2008 / Accepted: 15 April 2009/Published online: 5 May 2009

(C) The Author(s) 2009. This article is published with open access at Springerlink.com

\begin{abstract}
Background Obesity has been linked with a chronic state of inflammation which may be involved in the development of metabolic syndrome, cardiovascular disease, non-alcoholic steatohepatitis, and even cancer. The objective of this study was to examine the association between obesity class and levels of inflammatory biomarkers from men and women who participated in the 1999-2004 National Health and Nutrition Examination Survey (NHANES).

Methods Serum concentrations of C-reactive protein (CRP) and fibrinogen were measured among US participants of the 1999-2004 NHANES. We examined biomarker levels across different weight classes with normal weight, overweight, and obesity classes 1, 2, and 3 were defined as BMI of <25.0, 25.0-29.9, 30.0-34.9, 35.0-39.9, and $\geq 40.0$, respectively.

Results With CRP levels for normal weight individuals as a reference, CRP levels nearly doubled with each increase in weight class: $+0.11 \mathrm{mg} / \mathrm{dl}(95 \% \mathrm{CI}, 0.06-0.16)$ for overweight, $+0.21 \mathrm{mg} / \mathrm{dl}$ (95\% CI, 0.16-0.27) for obesity class $1,+0.43 \mathrm{mg} / \mathrm{dl}(95 \%$ CI, $0.26-0.61)$ for obesity class 2 , and $+0.73 \mathrm{mg} / \mathrm{dl}(95 \% \mathrm{CI}, 0.55-0.90)$ for obesity class 3 . With normal weight individuals as a reference, fibrinogen levels increase with increasing weight class and were highest for obesity class 3 individuals, +93.5 mg/dl (95\% CI, 72.9-114.1). Individuals with hypertension or diabetes have higher levels of CRP and fibrinogen levels compared to individuals without hypertension or diabetes, even when stratified according to BMI.

Conclusions There is a direct association between increasing obesity class and the presence of obesity-related comorbidities such as diabetes and hypertension with high levels of inflammatory biomarkers.
\end{abstract}

Keywords Inflammation $\cdot$ C-reactive protein · Fibrinogen · Obesity $\cdot$ Biomarker $\cdot$ Hypertension $\cdot$ Diabetes $\cdot$ NHANES

Presented at the 49th annual meeting of the Society for Surgery of the Alimentary Tract May 20, 2008, San Diego, CA.

X.-M. T. Nguyen · J. Lane • B. R. Smith • N. T. Nguyen

Department of Surgery,

University of California, Irvine Medical Center,

Orange, CA, USA

N. T. Nguyen $(\bowtie)$

Division of Gastrointestinal Surgery,

University of California, Irvine Medical Center,

333 City Blvd West, Suite 850,

Orange, CA 92868, USA

e-mail: Ninhn@uci.edu

\section{Introduction}

The prevalence of obesity in the United States is reaching epidemic proportions with one-third of the population being obese (BMI>30 kg/m²) and two-thirds being overweight. ${ }^{1}$ Health conditions associated with excess weight include increased risk for type II diabetes, hypertension, dyslipidemia, metabolic syndrome, atherosclerosis, degenerative joint disorders, obstructive sleep apnea, and certain cancers. $^{2-8}$ Obesity is also associated with cardiovascular disease which is the leading cause of mortality in the United States. ${ }^{9}$ While the mechanistic relationship between obesity and the development of obesity-related conditions are not clearly understood, there is growing evidence to support the role of inflammation as a possible link. ${ }^{10-13}$

C-reactive protein (CRP) and fibrinogen are biomarkers representing increased risk for cardiovascular morbidity and mortality. ${ }^{14,15} \mathrm{CRP}$, the most extensively studied inflam- 
matory biomarker, is a protein produced by hepatocytes in the presence of inflammation due to factors such as infection, injury, or conditions such as obesity. ${ }^{16}$ Elevated levels of CRP have been associated with increased inflammation in the coronary arteries, and thus a marker for increased risk for atherosclerosis and cardiovascular disease. $^{17,18}$ A meta-analysis of seven studies comparing individuals within the top third with those within the bottom third at study baseline showed that higher CRP levels were associated with a risk ratio of 1.7 (95\% CI 1.42.1) for coronary heart disease (CHD). ${ }^{19}$ Additionally, studies using older NHANES III (1988-1994) data have shown that levels of CRP are elevated in individuals with high BMI. $^{20,21}$ Another inflammatory biomarker that plays a direct role in coronary artery thrombosis is fibrinogen. ${ }^{22}$ Fibrinogen, a major coagulation protein and the precursor to fibrin, is a major determinant of platelet aggregation and plasma viscosity. ${ }^{23,24}$ To our knowledge, no studies to date have examined the relationship between fibrinogen levels and body weight, but a meta-analysis of 18 studies examining the association between fibrinogen and $\mathrm{CHD}$ found that individuals with fibrinogen values within the top third compared to individuals within the bottom third of the study distribution had a high risk ratio of 1.8 (95\% CI 1.62.0) for development of CHD. ${ }^{18}$ Since the relationship between obesity and cardiovascular disease, as well as the relationship between inflammation and cardiovascular disease, had been established, this study aimed to examine the association between obesity class and levels of inflammatory biomarkers (CRP and fibrinogen) utilizing more recent data from the National Health and Nutrition Examination Survey (NHANES) 1999-2004. We hypothesized that there is a direct relationship between the levels of inflammatory biomarkers with increasing degree of obesity and there is an interaction between level of biomarkers and diabetes and hypertension.

\section{Subjects and Methods}

\section{Study Population}

The NHANES is conducted by the National Center for Health Statistics which is part of the Centers for Disease Control and Prevention. The NHANES provides crosssectional health and nutrition data for the US population. The survey examines a nationally representative complex, multistage probability sample of about 5,000 US civilians each year, located within 15 counties across the country. The NHANES survey consists of an extensive health information interview, a complete physical examination, and extensive laboratory testing. The physical examinations were performed in a mobile examination center and all subjects signed a consent form approved by the Human Subjects Committee in the US Department of Health and Human Services. ${ }^{25-27}$ The three latest, continuous NHANES dataset were collected between 1999-2000, 2001-2002, and 2003-2004. Prior to 1999, the NHANES were performed in cluster as NHES I (1960-1962), NHANES I (1971-1974), NHANES II (1976-1980), and NHANES III (1988-1994).

Additional information from each participant was collected during an in-home interview and subsequent medical evaluation at a mobile examination center. During the in-home interview, information on age (limited to participants $\geq 20$ years), sex, race/ethnicity, smoking history, alcohol consumption, history of diabetes mellitus, history of arthritis, and medication usage was obtained. Participants currently smoking a cigarette, pipe and/or cigar were classified as smokers while alcohol consumption was defined as having at least one drink per week in the past 12 months. The prevalence of arthritis was self-reported and defined as ever being told by a doctor or health professional. At the mobile examination center, blood pressure measurements were taken by trained interviewers and physicians using standardized measurement protocols recommended by the American Heart Association. ${ }^{28}$ Height, weight, and lipid profile measurements were determined using standard protocols. More details are provided in the NHANES Laboratory/Medical Technologists Procedures Manual. ${ }^{29}$

Participants were considered to have hypertension if their mean systolic blood pressure, measured at the mobile examination center, was greater than $140 \mathrm{mmHg}$ or mean diastolic blood pressure was greater than $90 \mathrm{mmHg}$, if they were told by their doctor that they have high blood pressure or hypertension, or if they were taking antihypertensive medications. Diabetes mellitus was self-reported and defined to include subjects who were told by their doctor they have diabetes and subjects who stated that they were currently using antidiabetic medication(s) such as insulin or oral hypoglycemic agents.

\section{Definition of Obesity}

Body mass index (BMI) was calculated as weight in kilograms divided by the square of height in meters. The National Heart, Lung, and Blood Institute's definition for overweight and obesity were used to categorize the degree of obesity. A BMI <18.5 was categorized as underweight; a BMI between 18.5 and 24.9 was categorized as normal weight class; a BMI between 25.0 and 29.9 was categorized as overweight; a BMI between 30.0 and 34.9 was categorized as obesity class 1; a BMI between 35.0 and 39.9 was categorized as obesity class 2 ; and a BMI $\geq 40.0$ was categorized as obesity class 3 . In this study, we did not differentiate between normal weight and underweight class. 


\section{Biomarkers}

CRP concentrations were available for participants aged 3 years and older and fibrinogen concentrations were taken for individuals aged 40 years and older. Using blood samples collected from participants, CRP concentrations were determined using latex-enhanced nephelometry. Plasma fibrinogen levels were quantified using the Clauss clotting method and were only available for NHANES $1999-2002 .{ }^{30}$ We analyzed the levels of CRP and fibrinogen across the classes of obesity.

\section{Statistical Analysis}

All statistical analyses were conducted in SAS 9.1 (SAS Institute Inc., Cary, NC, USA). Due to the NHANES' complex probability sampling of the US population, sample weights, stratification, and clustering of the sampling design were incorporated into all SAS survey procedures to ensure the correct estimation of standard errors, confidence intervals and $p$ values. A 6-year sample weight was used for CRP analyses and a 4-year weight was used for the fibrinogen analysis. Two different sample weights were needed because CRP measurements were available for 1999-2004 surveys while fibrinogen was only measured between 1999 and 2002. These specific sample weights were created according to the National Center for Health Statistics guidelines to account for oversampling of certain age, sex, race/ethnicity domains and differential non-response or undercoverage. ${ }^{31}$

The initial study sample included 29,402 individuals with only 24,157 participants having CRP measurements. Since this study was limited to adult age 20 years or older, a total of 10,796 persons were excluded from the CRP analysis, yielding a total of 13,361 individuals for the final CRP analyses. Fibrinogen data was only publicly available for a subset of participants aged 40 years or older in the NHANES 1999-2002 giving a total of 5,690 persons for the analyses of fibrinogen levels. We limited our study sample to those age 20 years or older because only individuals with complete data for additional variables adjusted for in our analyses (i.e., smoking) were considered.

Unadjusted and adjusted linear regression models were designed to assess the association between obesity class (with normal weight $\left[\mathrm{BMI}<25.0 \mathrm{~kg} / \mathrm{m}^{2}\right]$ as the reference point) with CRP and fibrinogen levels. Adjusted models accounted for the possible effects of sex, age, race, smoking status, alcohol usage, arthritis status, blood pressure, and triglyceride levels. Analysis of variance was used to compare mean biomarker concentrations between all groups. To determine if mean biomarker concentrations differed between participants with hypertension and diabetes compared to participants without hypertension and diabetes according to obesity class, a multiplicative interaction term was created between the BMI variable and the dichotomous disease variable for inclusion in additional regression analyses. A similar strategy was applied to test for differences in biomarker marker levels by weight class and ethnicity. Unless otherwise noted, data are presented as mean \pm standard error (SE) and statistical significance was set at $p$ values $<0.05$.

\section{Results}

Table 1 lists the demographics of the study population according to obesity class. The majority of the study individuals were categorized as normal or overweight; 3,262 of the study participants were categorized as obesity class $1 ; 1,335$ of the study population were categorized as obesity class 2; and 827 individuals were categorized as obesity class 3 (BMI $\geq 40)$. Estimates for the presence of diabetes and hypertension within each of the weight classes shows that those in the normal weight group had the lowest prevalence of diabetes at $1.3 \%$ and hypertension at $6.8 \%$ while those in obesity class 3 had the highest prevalence for diabetes at $11.5 \%$ and hypertension at $45.2 \%$ (Table 1 ).

\section{Association between CRP Levels and Obesity Class}

The association between CRP and obesity class was initially examined using linear regression without adjustments and results were similar to those from adjusted linear regression (data not shown). Table 2 presents the change in CRP levels across weight classes after adjusting the regression model for age, gender, race/ethnicity, systolic blood pressure, diastolic blood pressure, triglyceride level, presence of arthritis, smoking status, and alcohol consumption. There was a positive association between CRP concentration and each of the BMI levels $(p<0.01)$. The mean CRP level for the reference group, which consisted of non-smoking, white males with a BMI $<25 \mathrm{~kg} / \mathrm{m}^{2}$, was $0.05 \mathrm{mg} / \mathrm{dl}$. With each increase in weight category, the mean CRP level increased by $0.11 \pm 0.03 \mathrm{mg} / \mathrm{dl}$ for the overweight group, $0.21 \pm 0.03 \mathrm{mg} / \mathrm{dl}$ for obesity class 1 individuals, $0.43 \pm 0.09 \mathrm{mg} / \mathrm{dl}$ for obesity class 2 individuals, and $0.73 \pm 0.09 \mathrm{mg} / \mathrm{dl}$ for obesity class 3 individuals. The largest increase in CRP concentration was among individuals in obesity class 3 . A test for trend showed that the overall increasing change in CRP concentrations was statistically significant $(p=0.04)$. Analysis on the relationship between BMI and CRP concentration persists when further stratified by ethnicity (Table 3 ).

Association between Fibrinogen Levels and Obesity Class

The association between fibrinogen and obesity class was initially examined using linear regression without adjust- 
Table 1 NHANES Population Characteristics by Body Mass Index Categories, 1999-2004

Body mass index categories, $\mathrm{kg} / \mathrm{m}^{2}$

\begin{tabular}{lllll}
\hline $\begin{array}{l}\text { Normal }(<25.0) \\
n=17,571\end{array}$ & $\begin{array}{l}\text { Overweight } \\
(25.0-29.9)\end{array} n=6,407$ & $\begin{array}{l}\text { Obesity class } 1 \\
(30.0-34.9) n=3,262\end{array}$ & $\begin{array}{l}\text { Obesity class } 2 \\
(35.0-39.9) n=1,335\end{array}$ & $\begin{array}{l}\text { Obesity class } 3 \\
(\geq 40.0) n=827\end{array}$ \\
\hline
\end{tabular}

Characteristics

\begin{tabular}{|c|c|c|c|c|c|}
\hline \multicolumn{6}{|l|}{ Age, $\%{ }^{\mathrm{a}}$} \\
\hline 20.0-29.9 years & $1,173(44.4)$ & $774(29.3)$ & $402(15.2)$ & $161(6.1)$ & $133(5.0)$ \\
\hline $30.0-39.9$ years & $880(36.3)$ & $795(32.8)$ & 434 (17.9) & $178(7.3)$ & $138(5.7)$ \\
\hline $40.0-49.9$ years & $693(29.3)$ & $838(35.4)$ & $479(20.2)$ & $213(9.0)$ & $146(6.2)$ \\
\hline $50.0-59.9$ years & $504(28.1)$ & $646(36.0)$ & $369(20.6)$ & $165(9.2)$ & $108(6.0)$ \\
\hline$\geq 60$ years & $1,649(33.0)$ & $1,869(37.5)$ & 939 (18.9) & $366(7.3)$ & $161(3.2)$ \\
\hline \multicolumn{6}{|l|}{ Gender, $\%{ }^{\mathrm{a}}$} \\
\hline Male & $8,696(60.4)$ & $3,431(23.8)$ & $1,512(10.5)$ & $504(3.5)$ & $248(1.7)$ \\
\hline Female & $8,875(59.1)$ & 2,976 (19.8) & $1,750(11.7)$ & $831(5.5)$ & $579(3.9)$ \\
\hline \multicolumn{6}{|l|}{ Race/ethnicity, $\%{ }^{\mathrm{a}}$} \\
\hline Non-Hispanic White & $6,301(56.0)$ & $2,752(24.5)$ & $1,382(12.3)$ & $522(4.6)$ & $293(2.6)$ \\
\hline Non-Hispanic Black & $4,524(62.3)$ & $1,293(17.8)$ & $743(10.2)$ & $390(5.4)$ & $312(4.3)$ \\
\hline Mexican American & $5,064(60.8)$ & $1,840(22.1)$ & 905 (10.9) & $345(4.1)$ & $170(2.0)$ \\
\hline Other $^{\mathrm{b}}$ & $1,682(65.5)$ & $522(20.3)$ & $232(9.0)$ & $78(3.0)$ & $52(2.0)$ \\
\hline Current smoker, $\%{ }^{\mathrm{a}}$ & $1,368(41.5)$ & $1,045(31.7)$ & $553(16.8)$ & $198(6.0)$ & $130(3.9)$ \\
\hline ystolic BP $(\mathrm{mmHg})^{\mathrm{c}}$ & $119.3 \pm 0.4$ & $124.1 \pm 0.5$ & $125.5 \pm 0.5$ & $126.8 \pm 0.7$ & $128.0 \pm 1.0$ \\
\hline iastolic BP $(\mathrm{mmHg})^{\mathrm{c}}$ & $70.2 \pm 0.3$ & $72.5 \pm 0.3$ & $73.7 \pm 0.4$ & $74.3 \pm 0.4$ & $75.0 \pm 0.6$ \\
\hline riglycerides $(\mathrm{mg} / \mathrm{dl})^{\mathrm{c}}$ & $118.0 \pm 3.7$ & $159.7 \pm 4.4$ & $177.8 \pm 7.2$ & $175.2 \pm 7.4$ & $170.5 \pm 6.8$ \\
\hline otal cholesterol $(\mathrm{mg} / \mathrm{dl})^{\mathrm{c}}$ & $195.3 \pm 0.9$ & $207.7 \pm 1.0$ & $207.5 \pm 1.2$ & $206.6 \pm 1.7$ & $197.7 \pm 1.8$ \\
\hline IDL cholesterol $(\mathrm{mg} / \mathrm{dl})^{\mathrm{c}}$ & $58.1 \pm 0.4$ & $50.9 \pm 0.3$ & $46.8 \pm 0.4$ & $46.6 \pm 0.5$ & $46.2 \pm 0.6$ \\
\hline $\mathrm{DL}$ cholesterol $(\mathrm{mg} / \mathrm{dl})^{\mathrm{c}}$ & $114.4 \pm 1.1$ & $125.2 \pm 1.0$ & $126.3 \pm 1.4$ & $122.8 \pm 2.2$ & $118.8 \pm 2.5$ \\
\hline Alcohol (drinks/day) ${ }^{\mathrm{c}}$ & $2.0 \pm 0.1$ & $2.1 \pm 0.1$ & $1.9 \pm 0.1$ & $1.9 \pm 0.2$ & $1.4 \pm 0.1$ \\
\hline -reactive protein $(\mathrm{mg} / \mathrm{dl})^{\mathrm{c}}$ & $0.3 \pm 0.01$ & $0.4 \pm 0.01$ & $0.5 \pm 0.01$ & $0.7 \pm 0.04$ & $1.1 \pm 0.06$ \\
\hline ibrinogen $(\mathrm{mg} / \mathrm{dl})^{\mathrm{c}, \mathrm{d}}$ & $354.3 \pm 4.4$ & $361.4 \pm 2.7$ & $376.6 \pm 3.2$ & $387.7 \pm 5.1$ & $436.9 \pm 7.2$ \\
\hline Diabetic, $\%^{\mathrm{a}}$ & $235(1.3)$ & $318(5.0)$ & $228(7.0)$ & $132(9.9)$ & $95(11.5)$ \\
\hline Hypertensive, $\%^{\mathrm{a}}$ & $1,194(6.8)$ & $1,624(25.3)$ & $1,089(33.4)$ & $533(39.9)$ & $374(45.2)$ \\
\hline
\end{tabular}

${ }^{\text {a }}$ Values depicted as $n(\%)$ of each row

${ }^{\mathrm{b}}$ Includes respondents indicating multiracial or an ethnicity other than Mexican American, Non-Hispanic White, or Non-Hispanic Black

${ }^{\mathrm{c}}$ Mean value \pm standard error

${ }^{\mathrm{d}}$ Fibrinogen measurements only available for individuals age 40 years and older participating in the NHANES 1999-2002 surveys

Table 2 Adjusted Linear Regression Analysis for the Association between Biomarker Levels and Obesity Class, NHANES 1999-2004

\begin{tabular}{lll}
\hline Obesity class (body mass index, $\left.\mathrm{kg} / \mathrm{m}^{2}\right)$ & Change in CRP level $(\mathrm{mg} / \mathrm{dl}) \pm \mathrm{SE}$ & Change in fibrinogen level (mg/dl) $\pm \mathrm{SE}$ \\
\hline Normal $(<25.0)$ & Reference $^{\mathrm{a}}$ & Reference $^{\mathrm{b}}$ \\
Overweight (25.0-29.9) & $0.11 \pm 0.03^{*}$ & $11.5 \pm 3.9^{*}$ \\
Obesity class 1 (30.0-34.9) & $0.21 \pm 0.03^{*}$ & $25.6 \pm 5.0^{*}$ \\
Obesity class II (35.0-39.9) & $0.43 \pm 0.09^{*}$ & $40.0 \pm 7.6^{*}$ \\
Obesity class III $(\geq 40.0)$ & $0.73 \pm 0.09^{*}$ & $93.5 \pm 10.1^{*}$
\end{tabular}

Regression model adjusted for age, gender, race/ethnicity, systolic blood pressure, diastolic blood pressure, triglyceride level, smoking, arthritis status, and alcohol

${ }^{*} p<0.01$, compared to reference value

${ }^{a}$ CRP reference value: $0.05 \mathrm{mg} / \mathrm{dl}$

${ }^{\mathrm{b}}$ Fibrinogen reference value: $287.28 \mathrm{mg} / \mathrm{dl}$ 
Table 3 CRP Levels According to Ethnicity, NHANES 1999-2004

\begin{tabular}{lllll}
\hline Obesity class (body mass index, $\left.\mathrm{kg} / \mathrm{m}^{2}\right)$ & \multicolumn{2}{l}{ Mean CRP level (mg/dl) \pm standard error } \\
\cline { 2 - 5 } & Non-Hispanic White & Non-Hispanic Black & Mexican American & Other \\
\hline Normal (<25.0) & $0.11 \pm 0.01 n=2,295$ & $0.12 \pm 0.01 n=2,657$ & $0.15 \pm 0.01 n=2,820$ & $0.13 \pm 0.01 n=725$ \\
Overweight (25.0-29.9) & $0.24 \pm 0.03 n=301$ & $0.24 \pm 0.03 n=411$ & $0.31 \pm 0.02 n=548$ & $0.20 \pm 0.03 n=99$ \\
Obesity class 1 (30.0-34.9) & $0.41 \pm 0.04 n=131$ & $0.54 \pm 0.08 n=189$ & $0.38 \pm 0.03 n=214$ & $0.30 \pm 0.05 n=53$ \\
Obesity class II (35.0-39.9) & $0.63 \pm 0.12 n=44$ & $0.42 \pm 0.06 n=83$ & $0.41 \pm 0.05 n=87$ & $0.66 \pm 0.34 n=12$ \\
Obesity class III $(\geq 40.0)$ & $0.89 \pm 0.17 n=15$ & $0.69 \pm 0.06 n=70$ & $0.78 \pm 0.15 n=34$ & $0.71 \pm 0.16 n=8$ \\
\hline
\end{tabular}

Within each obesity class, mean CRP concentration was significantly different across the ethnicity groups; $p$ value $<0.01$ for the interaction term for BMI and ethnicity

ments (data not shown), and results were similar to those found in the model that adjusted for age, gender, race/ethnicity, systolic blood pressure, diastolic blood pressure, triglyceride level, presence of arthritis, smoking status, and alcohol consumption. An upward trend was observed for mean fibrinogen levels across weight classes where concentrations ranged from $287.28 \mathrm{mg} / \mathrm{dl}$ for normal weight individuals to $380.78 \mathrm{mg} / \mathrm{dl}$ for obesity class 3 individuals $(p=0.04)$. With normal weight individuals as a reference, the mean fibrinogen levels for those in the overweight category increased by $11.5 \pm$ $0.01 \mathrm{mg} / \mathrm{dl}, 25.6 \pm 5.0 \mathrm{mg} / \mathrm{dl}$ for obesity class 1 individuals, $40.0 \pm 7.6 \mathrm{mg} / \mathrm{dl}$ for obesity class 2 individuals, and $93.5 \pm$ $10.1 \mathrm{mg} / \mathrm{dl}$ for obesity class 3 individuals (Table 2). Changes in fibrinogen levels across all weight classes compared to fibrinogen levels in the normal weight group were statistically significant $(p<0.01)$. The greatest increase in mean fibrinogen level was among the obesity class 3 group where mean fibrinogen levels increased by $32.5 \%$ compared to fibrinogen levels in the normal weight group. Analysis on the relationship between BMI and fibrinogen levels persists when further stratified by ethnicity (Table 4).

Association between Inflammatory Biomarkers with Diabetes and Hypertension

Results from regression analysis confirmed that a synergistic relationship exists between levels of inflammatory biomarkers with diabetes and hypertension, even when stratified by BMI. Within each BMI category, additional subgroups were created based on the presence or absence of diabetes or hypertension and the mean CRP and fibrinogen concentrations were determined. Individuals with diabetes had higher mean CRP and higher mean fibrinogen concentrations than individuals without diabetes even when stratified according to BMI (Tables 5 and 6). Similarly, individuals with hypertension had higher mean CRP and higher mean fibrinogen concentrations than individuals without hypertension even when stratified according to BMI (Tables 5 and 6).

\section{Discussion}

In this cross-sectional analysis of US men and women, the lowest concentrations of CRP and fibrinogen were found among normal weight individuals. As BMI ranges increased from overweight to obesity classes 1,2 , and 3, CRP concentration increased by $0.11 \pm 0.03 \mathrm{mg} / \mathrm{dl}, 0.21 \pm$ $0.03 \mathrm{mg} / \mathrm{dl}, 0.43 \pm 0.09 \mathrm{mg} / \mathrm{dl}$, and $0.73 \pm 0.09 \mathrm{mg} / \mathrm{dl}$, respectively, and fibrinogen levels increased by $11.5 \pm$ $3.9 \mathrm{mg} / \mathrm{dl}, 25.6 \pm 5.0 \mathrm{mg} / \mathrm{dl}, 40.0 \pm 7.6 \mathrm{mg} / \mathrm{dl}$ and $93.5 \pm$ $10.1 \mathrm{mg} / \mathrm{dl}$, respectively. The strongest association between obesity and change in biomarker concentration was observed among those in obesity class 3 .

Table 4 Fibrinogen Levels According to Ethnicity, NHANES 1999-2002

\begin{tabular}{|c|c|c|c|c|}
\hline \multirow[t]{2}{*}{ Obesity class (body mass index, $\mathrm{kg} / \mathrm{m}^{2}$ ) } & \multicolumn{4}{|c|}{ Mean fibrinogen level $(\mathrm{mg} / \mathrm{dl}) \pm$ standard error } \\
\hline & Non-Hispanic White & Non-Hispanic Black & Mexican American & Other \\
\hline Normal $(<25.0)$ & $352.41 \pm 5.21 n=1,045$ & $372.31 \pm 6.95 n=289$ & $360.94 \pm 9.09 n=304$ & $353.32 \pm 9.38 n=141$ \\
\hline Overweight (25.0-29.9) & $357.89 \pm 3.33 n=1,057$ & $380.96 \pm 5.52 n=347$ & $353.16 \pm 3.68 n=525$ & $374.17 \pm 7.32 n=162$ \\
\hline Obesity class 1 (30.0-34.9) & $373.94 \pm 3.77 n=557$ & $406.48 \pm 7.04 n=196$ & $364.60 \pm 5.62 n=272$ & $375.50 \pm 9.25 n=74$ \\
\hline Obesity class II (35.0-39.9) & $381.54 \pm 5.99 n=208$ & $418.82 \pm 10.74 n=118$ & $375.20 \pm 10.06 n=114$ & $403.49 \pm 16.54 n=23$ \\
\hline Obesity class III $(\geq 40.0)$ & $439.52 \pm 8.64 n=111$ & $432.99 \pm 9.78 n=82$ & $412.87 \pm 13.42 n=54$ & $436.15 \pm 31.49 n=11$ \\
\hline
\end{tabular}

Within each obesity class, mean fibrinogen concentration was significantly different across the ethnicity groups; $p$ value $=0.02$ for the interaction term for BMI and ethnicity 
Table 5 CRP Levels According to Diabetes and Hypertension Status, NHANES 1999-2004

Obesity class (body mass index, $\mathrm{kg} / \mathrm{m}^{2}$ )

Mean CRP level (mg/dl) \pm standard error

\begin{tabular}{|c|c|c|c|c|}
\hline & \\
\hline & No diabetes & Diabetes* & No hypertension & Hypertension** \\
\hline Normal $(<25.0)$ & $0.30 \pm 0.02 n=2,960$ & $0.63 \pm 0.11 n=196$ & $0.26 \pm 0.01 n=3,471$ & $0.48 \pm 0.04 n=1,039$ \\
\hline Overweight (25.0-29.9) & $0.36 \pm 0.01 n=2,940$ & $0.46 \pm 0.06 n=298$ & $0.35 \pm 0.01 n=3,179$ & $0.45 \pm 0.03 n=1,507$ \\
\hline Obesity class 1 (30.0-34.9) & $0.49 \pm 0.18 n=1,494$ & $0.55 \pm 0.04 n=214$ & $0.48 \pm 0.02 n=1,488$ & $0.54 \pm 0.02 n=1,009$ \\
\hline Obesity class II (35.0-39.9) & $0.70 \pm 0.04 n=543$ & $0.95 \pm 0.23 n=125$ & $0.68 \pm 0.05 n=529$ & $0.75 \pm 0.07 n=494$ \\
\hline Obesity class III $(\geq 40.0)$ & $1.01 \pm 0.06 n=358$ & $1.05 \pm 0.13 n=85$ & $0.99 \pm 0.08 n=303$ & $1.20 \pm 0.07 n=333$ \\
\hline
\end{tabular}

${ }^{*} p$ value $<0.01$, CRP levels and diabetes interaction using 2 -way ANOVA, ${ }^{*} p$ value $=0.06$, CRP levels and hypertension interaction using twoway ANOVA

We observed a strong association between increasing weight class and increasing CRP concentrations. Compared to normal weight individuals, there was a 2-fold increase in mean CRP levels in overweight individuals; a 4-fold increase in obesity class 1 individuals; and an 8-fold and 14-fold increase among obesity class 2 and obesity class 3 individuals, respectively. Using data from NHANES III (1988-1994), Ford similarly found that CRP concentrations increased across six weight categories $(\mathrm{BMI}<18.5,18.5$ to $<25,25$ to $<30,30$ to $<35,35$ to $<40$, and $\geq 40 \mathrm{~kg} / \mathrm{m}^{2}$ ). Ford also found that the odds ratio for elevated CRP levels above the 85th percentile for BMI of 25 to $<30$ was $1.51(95 \%$ CI $1.23,3.86)$; 3.19 (95\% CI 2.60, 3.91) for BMI of 30 to $<35$; $6.11(95 \%$ CI $4.67,7.98)$ for BMI 35 to $<40$; and 9.30 (95\% CI 6.43-13.46) for those with BMI $\geq 40$ compared to those with BMI $<25 \mathrm{~kg} / \mathrm{m}^{2} .{ }^{19}$ Similarly, Visser and colleagues found that, with increasing BMI, the presence of elevated CRP levels, defined as CRP $\geq 0.22 \mathrm{mg} / \mathrm{dl}$, increases for both overweight and obese $\left(\geq 30 \mathrm{~kg} / \mathrm{m}^{2}\right)$ groups. Visser and colleagues also found that overweight men and overweight women were 1.41 (95\% CI 1.09, 1.81) and $2.23(95 \%$ CI $1.86,2.67)$ times more likely to have elevated CRP levels compared to normal-weight counterparts. ${ }^{20}$

The normal range for fibrinogen is between 200 and $400 \mathrm{mg} / \mathrm{dl}^{32,33} \mathrm{In}$ our adjusted regression analysis between fibrinogen levels and weight class, being in the overweight, obesity class 1 , obesity class 2 , and obesity class 3 groups placed individuals increasingly near the upper limit of normal fibrinogen levels. Elevated fibrinogen levels have been previously shown to associate with insulin resistance and atherosclerosis. ${ }^{34}$ We also examined fibrinogen concentrations across weight class according to diabetes status. Our findings suggest that increasing severity of obesity is associated with increased risk for diabetes. The results also support the idea that inflammation may play a role in the development of insulin resistance, ${ }^{35}$ underlying the importance of having a normal BMI to prevent the disease onset.

In addition to what has been presented in past studies, this study quantifies the estimated change in biomarker concentrations across different weight classes. As anticipated, those individuals in the highest weight class, obesity class 3 , had significantly higher CRP and fibrinogen concentrations relative to the normal BMI group as well as the other weight groups. This trend did not change with adjustments for age, gender, arthritis status, race/ethnicity, or smoking, suggesting that the observed CRP-obesity relationship is not due to other factors possibly affecting CRP levels and/or weight status. When we stratified by diabetes status, we also found that individuals in obesity class 3 had higher biomarker levels than those in obesity classes 1 and 2. This was also observed when we compared

Table 6 Fibrinogen Levels According to Diabetes and Hypertension Status, NHANES 1999-2002

\begin{tabular}{|c|c|c|c|c|}
\hline \multirow[t]{2}{*}{ Obesity class (body mass index, $\mathrm{kg} / \mathrm{m}^{2}$ ) } & \multicolumn{4}{|c|}{ Mean fibrinogen level $(\mathrm{mg} / \mathrm{dl}) \pm$ standard error } \\
\hline & No diabetes & Diabetes* & No hypertension & Hypertension** \\
\hline Normal $(<25.0)$ & $357.5 \pm 6.3 n=890$ & $413.4 \pm 15.4 n=100$ & $343.8 \pm 4.9 n=1,160$ & $381.4 \pm 5.5 n=618$ \\
\hline Overweight (25.0-29.9) & $364.3 \pm 3.8 n=964$ & $380.7 \pm 15.8 n=139$ & $353.2 \pm 2.7 n=1,239$ & $375.9 \pm 3.9 n=851$ \\
\hline Obesity class $1(30.0-34.9)$ & $375.2 \pm 5.3 n=469$ & $402.1 \pm 7.5 n=85$ & $372.8 \pm 4.4 n=535$ & $380.5 \pm 4.9 n=564$ \\
\hline Obesity class II (35.0-39.9) & $400.6 \pm 7.2 n=178$ & $410.9 \pm 11.6 n=50$ & $383.1 \pm 8.0 n=206$ & $392.1 \pm 7.5 n=257$ \\
\hline Obesity class III $(\geq 40.0)$ & $441.7 \pm 9.6 n=102$ & $444.1 \pm 15.8 n=33$ & $438.9 \pm 12.9 n=90$ & $435.8 \pm 7.7 n=168$ \\
\hline
\end{tabular}

${ }^{*} p$ value $=0.09$, fibrinogen levels and diabetes interaction using two-way ANOVA, ${ }^{*} p$ value $<0.01$, fibrinogen levels and hypertension interaction using two-way ANOVA 
CRP levels between diabetics and non-diabetics in obesity class 3 to those in the overweight and normal weight categories. Extending our analyses, we also stratified by hypertension status, reporting the mean biomarker concentrations within each weight class for a representative US population. The general trend supports our primary hypothesis that inflammation severity, indicated by elevated biomarker levels, directly correlates to weight class.

Inflammation in the presence of obesity is thought to arise primarily in adipose tissue as a result of chronic disruption of metabolic homeostasis, which leads to increased cytokine production and the activation of inflammatory signaling pathways in the body. ${ }^{12,13,36} \mathrm{~A}$ recent clinical study by Madsen and colleagues investigated the effects of short-term and long-term weight loss on levels of CRP and fibrinogen among obese subjects and found that long-term weight loss was associated with decreased CRP and fibrinogen concentrations. ${ }^{37}$ A systematic review found that for each $1 \mathrm{~kg}$ of weight loss, mean CRP levels were reduced by $0.13 \mathrm{mg} / \mathrm{l}^{38}$ Moderate, short-term weight loss, however, was shown to have no effect on fibrinogen levels, ${ }^{23}$ suggesting that long-term weight loss solutions through lifestyle changes or surgical intervention may be more useful for reducing inflammation and related disease risks.

Limitations of this study include the lack of repeated measurements of biomarker levels as well as the absence of information regarding any previous medical or surgical treatment for obesity. Additionally, the extent of our study on inflammatory biomarkers was limited by the availability of biomarker measurements in the NHANES dataset; we did not have the opportunity to access other markers of inflammation such as interleukin-6 or TNF-alpha. The population used for our CRP analyses also differed from the population used for the fibrinogen analysis because fibrinogen data was only collected among those who were 40 years of age and older between 1999 and 2002 while CRP measurements were taken among those who were 20 years of age and older between 1999 and 2004. There is also the possibility for information and recall bias in this study because data on hypertension, arthritis, and diabetic status were collected by means of self-report. However, in this study, possible information and recall biases were minimized by taking into account additional data collected on hypertension and diabetes medication usage as well as any relevant examination or laboratory data. Additionally, the under- or over-reporting of hypertension and diabetes should be similar across BMI categories. Despite these limitations, this study utilizes a large, comprehensive data set that serves as a representative sample of the US population, allowing for greater generalizability of the study results. Multiple markers of inflammation were also assessed, which increased the possibility of capturing a more complete description of inflammatory status among individuals. Future studies are needed to determine if the changes in inflammatory markers further differ among obese individuals, and whether inflammatory biomarker levels decrease at a different rate and by different amounts in obesity class 1 vs. obesity class 2 or 3 . If trends from this current study are persistent in such future studies, we anticipate that changes in levels of inflammatory biomarkers will differ according to weight class. Thus, the current findings of an association of CRP and fibrinogen and body weight, if causal, would imply that weight reduction leads to reduced prevalence of inflammation with attendant public health benefits.

\section{Conclusions}

This study demonstrates that levels of inflammatory biomarkers vary across weight classes, and that this difference in CRP and fibrinogen concentration is persistent when patients are subgrouped by ethnicity and by the presence or absence of diabetes and hypertension. As shown in our analyses, an increase in severity of obesity corresponded to higher CRP and fibrinogen levels. Such elevated biomarker concentrations based on a 6-year period (1999-2004) suggest that the optimal weight class should be within normal range of having a BMI less than 25.0 to possibly reduce the burden of obesity-related comorbidities in the US.

Open Access This article is distributed under the terms of the Creative Commons Attribution Noncommercial License which permits any noncommercial use, distribution, and reproduction in any medium, provided the original author(s) and source are credited.

\section{References}

1. Ogden CL, Carroll MD, Curtin LR, McDowell MA, Tabak CJ, Flegal KM. Prevalence of overweight and obesity in the United States, 1999-2004. JAMA 2006;295(13):1549-1555. doi:10.1001/ jama.295.13.1549.

2. Mokdad AH, Ford ES, Bowman BA, Dietz WH, Vinicor F, Bales VS, Marks JS. Prevalence of obesity, diabetes, and obesity-related health risk factors, 2001. JAMA 2003;289:76-79. doi:10.1001/ jama.289.1.76.

3. Solá E, Vayá A, Simó M, Hernández-Mijares A, Morillas C, España F, Estellés A, Corella D. Fibrinogen, plasma viscosity and blood viscosity in obesity. Relationship with insulin resistance. Clin Hemorheol Microcirc. 2007;37(4):309-318.

4. Must A, Spadano J, Coakley EH, et al. The disease burden associated with overweight and obesity. JAMA 1999;282:15231529. doi:10.1001/jama.282.16.1523.

5. Ford ES, Giles WH, Dietz WH. Prevalence of the metabolic syndrome among US adults: findings from the Third National Health and Nutrition Examination Survey. JAMA 2002;287:356359. doi:10.1001/jama.287.3.356. 
6. Crummy F, Piper AJ, Naughton MT. Obesity and the lung: 2. Obesity and sleep-disordered breathing. Thorax 2008;63(8):738746. doi: $10.1136 /$ thx.2007.086843.

7. Wilson PW, D'Agostino RB, Sullivan L, Parise H, Kannel WB. Overweight and obesity as determinants of cardiovascular risk: the Framingham experience. Arch Intern Med. 2002;162:1867-1872. doi:10.1001/archinte.162.16.1867.

8. Messier SP. Obesity and osteoarthritis: disease genesis and nonpharmacological weight management. Rheum Dis Clin North Am. 2008;34(3):713-729. doi:10.1016/j.rdc.2008.04.007.

9. Kung HC, Hoyert DL, Xu JQ, Murphy SL. Deaths: Final Data for 2005. National Vital Statistics Reports; vol 56 no 10. Hyattsville: National Center for Health Statistics, 2008.

10. Vgontzas AN. Does obesity play a major role in the pathogenesis of sleep apnoea and its associated manifestations via inflammation, visceral adiposity, and insulin resistance. Arch Physiol Biochem. 2008;114(4):211-223. doi:10.1080/13813450802364627.

11. Calabro P, Yeh ET. Intra-abdominal adiposity, inflammation, and cardiovascular risk: new insight into global cardiometabolic risk. Curr Hypertens Rep Reb. 2008;10(1):32-38.

12. Engstrom G, Hedblad B, Stavenow L, Jonsson S, Lind P, Janzon $\mathrm{L}$, et al. Incidence of obesity-associated cardiovascular disease is related to inflammation-sensitive plasma proteins: a populationbased cohort study. Arterioscler Thromb Vasc Biol. 2004;24:1498-1502. doi:10.1161/01.ATV.0000134293.31512.be.

13. Hotamisligil GS. Inflammation and metabolic disorders. Nature 2006;444:860-867. doi:10.1038/nature05485.

14. Kannel WB, D'Agostino RB, Wilson PW, Belanger AJ, Gagnon DR. Diabetes, fibrinogen, and risk of cardiovascular disease: the Framingham experience. Am Heart J. 1990;120(3):672-676. doi:10.1016/0002-8703(90)90026-T.

15. Fibrinogen Studies Collaboration. Plasma fibrinogen level and the risk of major cardiovascular diseases and nonvascular mortality: an individual participant meta-analysis. JAMA 2005;294 (14):1799-1809. doi:10.1001/jama.294.14.1799.

16. Pepys MB. The acute phase response and C-reactive protein. Oxford Textbook of Medicine. In Weatherall DJ, Ledingham JGG, Warrell DA, eds. New York: Oxford University Press, 1996, pp. 1527-1533.

17. Bisoendial RJ, Kastelein JJ, Stroes ES. C-reactive protein and atherogenesis: from fatty streak to clinical event. Atherosclerosis 2007;195(2):e10-18. doi:10.1016/j.atherosclerosis.2007.04.053.

18. Rifai N, Ridker PM. Inflammatory markers and coronary heart disease. Curr Opin Lipidol. 2002;13(4):383-389. doi:10.1097/ 00041433-200208000-00005.

19. Danesh J, Collins R, Appleby P, Peto R. Association of fibrinogen, C-reactive protein, albumin, or leukocyte count with coronary heart disease: meta-analyses of prospective studies. JAMA 1998;279(18):1477-1482. doi:10.1001/jama.279.18.1477.

20. Ford ES. Body mass index, diabetes, and C-reactive protein among U.S. adults. Diabetes Care 1999;22(12):1971-1977. doi:10.2337/diacare.22.12.1971.

21. Visser M, Bouter LM, McQuillan GM, Wener MH, Harris TB. Elevated C-reactive protein levels in overweight and obese adults. JAMA 1999;282:2131-2135. doi:10.1001/jama.282.22.2131.

22. Ernst E. Fibrinogen as a cardiovascular risk factor-interrelationship with infections and inflammation. Eur Heart J. 1993;14 (Suppl K):82-87.

23. Kakafika AI, Liberopoulos EN, Mikhailidis DP. Fibrinogen: a predictor of vascular disease. Curr Pharm Des. 2007;13(16):16471659. doi:10.2174/138161207780831310.

24. Solá E, Vayá A, Simó M, Hernández-Mijares A, Morillas C, España F, Estellés A, Corella D. Fibrinogen, plasma viscosity and blood viscosity in obesity. Relationship with insulin resistance. Clin Hemorheol Microcirc. 2007;37(4):309-318.

25. National Center for Health Statistics. NHANES 1999-2000 Public Data Release File Documentation. Available online from: http:// www.cdc.gov/nchs/data/nhanes/gendoc.pdf [Accessed April 2008]. 2008.

26. National Center for Health Statistics. NHANES 2001-2002 Public Data Release File Documentation. Available online from: http:// www.cdc.gov/nchs/data/nhanes/nhanes_01_02/general_data_release_doc.pdf [Accessed April 2008]. 2008.

27. National Center for Health Statistics. NHANES 2003-2004 Public Data Release File Documentation. Available online from: http:// www.cdc.gov/nchs/data/nhanes/nhanes_03_04/general_data_release_doc_03-04.pdf [Accessed April 2008]. 2008.

28. Blood pressure levels. In: Heart and stroke encyclopedia: A-Z guide. Dallas, TX: American Heart Association, Available online from: http:www.americanheart.org/Heart_and_Stroke_A_Z_ Guide/bplev.html 2000.

29. Centers for Disease Control and Prevention. NHANES Laboratory/Medical Technologists Procedures Manual. Atlanta, GA: Centers for Disease Control and Prevention, April 2001. Available online from: www.cdc.gov/nchs/data/nhanes/lab1-6.pdf [Accessed April 2008].

30. National Health and Nutrition Examination Survey Laboratory Protocol for CRP and fibrinogen. Hyattsville, MD: U.S. Department of Health and Human Services, Centers for Disease Control and Prevention, Available online from: http://www.cdc. gov/nchs/data/nhanes/frequency/lab11doc.pdf [Accessed April 2008]. 2008.

31. Centers for Disease Control and Prevention (CDC). National Center for Health Statistics (NCHS). National Health and Nutrition Examination Survey Data. Hyattsville, MD: U.S. Department of Health and Human Services, Centers for Disease Control and Prevention; 1999-2004. http://www.cdc.gov/nchs/ nhanes.htm

32. Hoffman R, Benz EJ Jr, Shattil SJ, et al, eds. Hematology: Basic Principles and Practice. 4th ed. Philadelphia: Churchill Livingstone, 2005:2097.

33. McPherson RA, Pincus MR. Henry's Clinical Diagnosis and Management by Laboratory Methods, 21st ed. Philadelphia: Saunders, 2007, p 239.

34. Theuma P, Fonseca VA. Inflammation, insulin resistance, and atherosclerosis. Metab Syndr Relat Disord. 2004;2(2):105-113. doi:10.1089/met.2004.2.105.

35. Bastard JP, Maachi M, Lagathu C, Kim MJ, Caron M, Vidal H, Capeau J, Feve B. Recent advances in the relationship between obesity, inflammation, and insulin resistance. Eur Cytokine Netw. 2006;17(1):4-12.

36. Yudkin JS, Stehouwer CD, Emeis JJ, Coppack SW. C-reactive protein in healthy subjects: associations with obesity, insulin resistance, and endothelial dysfunction: a potential role for cytokines originating from adipose tissue. Arterioscler Thromb Vasc Biol. 1999;19:972-8.

37. Madsen EL, Rissanen A, Bruun JM, Skogstrand K, Tonstad S, Hougaard DM, Richelsen B. Weight loss larger than $10 \%$ is needed for general improvement of levels of circulating adiponectin and markers of inflammation in obese subjects: a 3-year weight loss study. Eur J Endocrinol. 2008;158(2):179-187. doi:10.1530/EJE-07-0721.

38. Selvin E, Paynter NP, Erlinger TP. The effect of weight loss on Creactive protein: a systematic review. Arch Intern Med. 2007;167 (1):31-39. doi:10.1001/archinte.167.1.31. 